\title{
Guillermo de Torre y el catálogo de la editorial Losada
}

\author{
Guillermo de Torre and the catalog of the Losada publishing
}

\section{FERNANDO LARRAZ}

UNIVERSIDAD DE ALCALÁ DE HENARES (ESPAÑA) · fernando.larraz@uah.es

Su área de especialización es la historia de la cultura y la literatura españolas de los siglos XX-XXI. Ha publicado cuatro monografías -El monopolio de la palabra. El exilio intelectual en la España franquista (Madrid, 2009), Una historia transatlántica del libro. Relaciones editoriales entre España y América Latina (1936-1950) (Gijón, 2010), Max Aub y la historia literaria (Berlín, 2014) y Letricidio español. Novela y censura durante el franquismo (Gijón, 2014)- y editó el volumen colectivo Estudios de literatura, cultura e historia contemporánea en homenaje a Francisco Caudet (Madrid, 2015). Es autor, además, de artículos publicados en revistas académicas de América y Europa. Ha colaborado como crítico literario con varios periódicos. Actualmente dirige o codirige las revistas Puentes de Crítica Literaria y Cultural y Contrapunto -de las que fue fundadory Represura.

RECIBIDO: 16 de diciembre de 2015

ACEPTADO: 22 de mayo 2016

RESUMEN: Este trabajo intenta establecer las causas que expliquen por qué Editorial Losada, cuyo catálogo había incluido muchos de los títulos más relevantes de la literatura latinoamericana y argentina de los años cuarenta, comenzó a experimentar un declive a causa de su evolución conservadora en el terreno formal en 1955. Entre estos factores se destaca la renuncia de Guillermo de Torre como director editorial en 1955 y se explica el papel que el crítico y editor tuvo en la evolución del proyecto editorial.

PALABRAS ClAVE: Losada, literatura argentina, Guillermo de Torre.
ABSTRACT: This paper tries to set the causes which explain why the Publishing Company Losada, whose catalogue had included many of the most relevant books of Latin American Literature during the 1940s, began to experience a decline because of its progressive conservative forms. Among these factors, it is outlined the resignation of Guillermo de Torre as editorial director in 1955, and it is explained the role that he had in the development of this publishing project.

KEY WORDS: Losada, Argentinian literature, Guillermo de Torre.

Larraz, Fernando. "Guillermo de Torre y el catálogo de la editorial Losada".

Kamchatka. Revista de análisis cultural 7 (Junio 2016): 59-71

DOI: 10.7203/KAM.7.7683 ISSN: 2340-1869 
En uno de los trabajos que integran su libro La otra cara de Jano titulado "La literatura latinoamericana en el proyecto editorial de Losada”, José Luis de Diego analiza el recorrido histórico del catálogo de la editorial y apunta cómo, después de haber representado la vanguardia literaria e intelectual en América Latina, en los años cincuenta, la selección de su catálogo quedó angostada por un realismo estrecho y conservador, muy apegado a ideas de compromiso que lo alejaron de los grandes autores del boom de los años sesenta: "solo podemos conjeturar que una concepción estética demasiado estrecha o conservadora por parte de quienes tomaban las decisiones fue dejando a la editorial al margen de los procesos de renovación literaria” (De Diego 2015: 152). Las páginas que siguen parten de estas observaciones, que De Diego sustenta en numerosas evidencias emanadas de un análisis minucioso del catálogo, así como de la causa que, al final de este artículo, De Diego propone: "La caída del peronismo posibilitó el ingreso a las universidades de buena parte del grupo fundacional, de donde la coherencia inicial se fue resquebrajando" (De Diego 2015: 159). En concreto, me propongo ensayar un sintético estudio de la evolución del catálogo de la editorial, poniéndolo en paralelo con los cambios organizativos que tuvieron lugar en la estructura de Losada y, sobre todo, con la posición que en cada momento ocupó Guillermo de Torre en ella.

La editorial Losada es una de las llamadas, quizá equívocamente, editoriales del exilio. Su fundador, Gonzalo Losada, si bien era un español de ideas republicanas, residía en Buenos Aires desde 1928. Y aunque muchos de los colaboradores que fueron sumándose al proyecto a partir de 1939 eran, en efecto, exiliados del régimen franquista, no puede decirse esto mismo del núcleo de intelectuales y empresarios que fundó la editorial en verano de 1938, casi un año antes de que terminara la guerra en España. El mismo Guillermo de Torre, uno de sus más estrechos colaboradores desde el inicio de la editorial, tampoco era en sentido estricto un exiliado, pues su salida de España se había producido a los pocos días de producirse la rebelión militar y, por tanto, mucho antes de que el desenlace de la guerra estuviera claro.

En cualquier caso, el problema fundamental que debían resolver los editores de Losada era el mismo que el de la mayoría de casas editoriales fundadas en aquellos años y participadas por españoles: hallar la manera de resolver satisfactoriamente la ecuación entre, por una parte, la defensa y divulgación de una cultura escrita española de raigambre laica, democrática y republicana, proscrita en la España franquista $-\mathrm{y}$, al mismo tiempo, contrarrestar la política de propaganda del franquismo en tierras americanas-, y, por otra parte, sortear el riesgo de un reduccionismo nacionalista que cerrara la editorial a la novedad que suponía Latinoamérica, con una cultura mucho más abierta y fructífera que la de la vieja metrópoli. Mucho más cuando la empresa tenía una vocación fundacional de arraigarse en el campo cultural argentino y no estaba sometida a la contingencia de un exilio virtualmente corto y de la consiguiente repatriación del catálogo a España, como sí ocurría con otros proyectos editoriales 
coetáneos en México. Losada, en efecto, fue concebida con amplios niveles de profesionalidad y sin limitar su política editorial a un fin político ni a la formación cultural de una colectividad regional.

Guillermo de Torre había llegado a Buenos Aires por primera vez en 1927, un año antes que Gonzalo Losada. Había colaborado entonces estrechamente con varias empresas culturales. Entre ellas, además de la revista y editorial Sur, estaba la delegación en Argentina de Espasa Calpe, bajo la dirección de Julián Urgoiti, para la que hizo trabajos diversos hasta su regreso a España en 1931. De Torre era una personalidad vinculada muy estrechamente con la industria del libro desde antes de su llegada a Buenos Aires. Era además, con menos de treinta años de edad, uno de los mejores conocedores de la literatura americana contemporánea y uno de los intelectuales con una visión transatlántica más clara. La autoría del artículo "Madrid, meridiano intelectual de Hispanoamérica" (Alemany 1998), en el que defiende el padrinazgo editorial de España sobre América, es una muestra de cómo ya unos meses antes de salir rumbo a Argentina, De Torre está abogando por intereses corporativos de la industria del libro española en un contexto de creciente conflictividad empresarial, que no escondía tintes neocolonialistas (Martínez Rus 2002). Aquel artículo había aparecido en abril de 1927 y, en medio de la polémica con la revista Martín Fierro, a finales de verano de ese año, De Torre había viajado por primera vez a Buenos Aires, donde permaneció cuatro años y medio. En una carta de noviembre de 1927, cuando De Torre lleva dos meses en Argentina, le escribe a Nicolás M. de Urgoiti que “con su primo Julián he trabado una excelente amistad, que llega hasta la cooperación, pues me ha encargado de algunos asuntos de publicidad y de asesoría literaria en la editorial". Y habla de "hispanoamericanismo intelectual" y de "aproximación de ambas culturas", coordinada mediante una acción editorial (García y Sanz 2012: 190). Los contactos con la editorial -y, sobre todo, con la delegación argentina de la misma- son estrechos. Inicia una amistad particularmente fecunda con el gerente de la delegación, Gonzalo Losada, quien, una vez que De Torre regresa a España, le escribe con frecuencia en términos amistosos y muy encomiásticos, como cuando le dice que "lleva Vd. camino de ser el mejor crítico literario y de arte de lengua castellana, lo que es mucho decir en estos tiempos”. También es muy reseñable su trabajo como secretario de Sur, la revista que funda en 1931 Victoria Ocampo, quien recuerda que "Mallea, iniciador de Sur, y de Torre, secretario, ocupaban un lugar mucho más importante que el de simples consejeros: juntos hacíamos la revista" (Ocampo 1966: 9).

A los dos meses de estallar la guerra española, en septiembre de 1936, Guillermo de Torre se instala en París con su mujer, Norah Borges, que está a punto de dar a luz a su primer hijo, Luis. Desde allí, el 14 de diciembre de 1936, contacta con Losada y Julián Urgoiti y se pone a su disposición y proponiéndoles su colaboración en futuros planes editoriales relacionados con la parálisis de la producción librera en España a causa de la guerra. Losada y Urgoiti responden el 16 de enero: "Como Ud. lo supone no recibimos libros de ninguna especie desde hace ya bastante tiempo y vemos 
aproximarse con gran preocupación ese momento aciago en que nos quedemos prácticamente sin libros ni forma de evolucionar aquí". Y prosiguen:

Ahora bien si los hechos nos llevan a tener que desenvolvernos en la Argentina con nuestros propios medios, inútil decirle que sería muy grato para nosotros dos contar con su experta colaboración y como en definitiva ya han resuelto Uds. Su venida a la Argentina allá para el próximo abril [...] creemos que sería muy conveniente que viniera Ud. bien documentado en materia de catálogos, autores, etc. Por si pudiéramos llegar a una inteligencia para llevar a la práctica un plan de publicaciones en Argentina.

La carta es de singular importancia, en la medida en que refleja de manera muy nítida cómo la guerra española permitió a los editores argentinos, incluso a aquellos vinculados tradicionalmente con la industria española, imaginar una autonomía editorial en la que el contacto con otros ámbitos lingüísticos no estaría ya determinado por el meridiano madrileño que el propio De Torre había declarado -y celebrado- diez años antes. Aquel "desenvolvernos en la Argentina con nuestros propios medios" iba a concretarse poco después con la fundación de Espasa Calpe Argentina y, algunos meses más tarde, en la editorial Losada. Por otra parte, De Torre aparece en estas cartas como una figura providencial en este sentido para Losada y Urgoiti, habituados a la gestión editorial, pero no al trabajo de selección y preparación de textos, y se le encarga que vaya atisbando posibilidades de futuros rumbos editoriales. Tampoco son desdeñables de esta carta las reservas que al final de la misma los editores muestran acerca de la rentabilidad de los libros de naturaleza literaria:

La venta del libro literario no da pie para sostener una casa como la nuestra, pues si ya resulta problemática la existencia de casas que viven en España de la producción literaria con un mercado total mucho más amplio y una organización distribuidora montada a la perfección, ¿̨a qué consumos pueden aspirarse en la Argentina en que el radio de acción se reduce considerablemente sobre todo ahora en que nos faltaría el mercado español?

Esta desconfianza de los editores hacia la virtual rentabilidad del libro literario, como veremos, será una constante en la carrera profesional de Gonzalo Losada.

La segunda llegada de De Torre a Buenos Aires, en abril de 1937, casi coincide con la decisión del consejo de administración de Espasa- Calpe, reunido en San Sebastián, de ceder poderes a Urgoiti y Losada para reconvertir la delegación de Buenos Aires en una editorial independiente (Durán 1998). La nueva empresa tendría el nombre de Compañía Anónima Editora Espasa Calpe Argentina. El objetivo era dotarla de mayor independencia en su actuación y centralizar la labor en América de la forma más conveniente a los intereses de la editorial, ya que la guerra impedía editar en España, donde además, los talleres habían sido incautados.

En el primer directorio de la empresa Espasa Calpe Editores, S.A. figuraba ya, junto al propio Losada, Guillermo de Torre. Como ha sido ya varias veces explicado (Larraz 2009), aquello duró poco 
más de un año, debido a la injerencia política de los dueños de Espasa Calpe en las labores de la recién creada editorial porteña. Losada había proyectado la publicación de títulos de autores argentinos, como Manuel Gálvez, planes que fueron revertidos con la orden estricta de no publicar ningún libro sin permiso expreso de España. A esto se sumó la intromisión que supuso la llegada de Manuel Olarra como nuevo delegado de la casa editorial a Buenos Aires con expresas instrucciones de la dirección de reorientar las publicaciones hacia los intereses político-comerciales de la España franquista.

Las ideas políticas de De Torre por aquel entonces no difieren de las de Losada: un republicanismo moderado y netamente liberal que, sin embargo, resulta excesivo para los propietarios de la editorial y que impulsa a ambos a dejar Espasa Calpe, al igual que Julián Urgoiti. Casi inmediatamente Losada y De Torre participan en la fundación el nuevo sello, que lleva el nombre de Losada, y al que se unen otros colaboradores destacados de Espasa Calpe Argentina. Varios testimonios confirman que fueron motivos ideológicos los que llevaron a Losada y De Torre a dejar la editorial. Entre los más conocidos está el de Pedro Henríquez Ureña, uno de los fundadores de la nueva editorial, a Alfonso Reyes, a quien le cuenta en carta del 8 de agosto de 1938, que "Espasa Calpe Argentina, bajo la presión del franquismo, se ha reducido a poca cosa. No puede publicar sino libros de ultraderecha o libros antiguos inofensivos. Los que allí estábamos -Guillermo de Torre, el pintor Atilio Rossi y yo; medio afuera y medio adentro, Romero y Amado - nos hemos ido con Gonzalo Losada, ex gerente de Calpe, que ha fundado una casa editorial" (De Lara 1983: 444).

Pero quizá nos interese más la opinión, con valoraciones radicalmente diferentes, de Victoria Ocampo, quien escribe a Ortega y Gasset, por entonces todavía en París, lo siguiente: "Me permito, Ortega, prevenirle para que no se sorprenda su buena fe, pues el señor que se separa de Espasa Calpe debe hacerlo -no lo sé- por razones políticas y se teme que reciban fondos de esa turbia fuente que prolonga la tragedia de España" (Campomar Fornieles 2010: 130). No parece que hubiera tal y no sabemos si Ocampo contaba con alguna fuente para suponer que la nueva editorial gozaba de financiación estatal: la constitución de la editorial Losada como Sociedad Anónima se hizo con las aportaciones de una serie de inversores a cuyo frente estaba Losada con sus propios fondos. No obstante, la conclusión a la que llega Ortega la expresa por carta, desde San Juan de Luz a París, a su amigo Gregorio Marañón: “Losada se ha separado con algunos muchachos de la izquierda y ha creado una editorial cuyo capital, de cuantía desconocida, no tiene un origen todavía notorio. Es resueltamente una editorial roja. Yo no sé esto por Olarra, que aún no me ha escrito allí, sino por otras personas" (López Vega 2008: 197). Aparte de revelar lo equivocado de los juicios de Ortega sobre la nueva editorial y aun sobre las posiciones intelectuales sobre la guerra, el fragmento evidencia la larga sombra que proyectaba la figura intelectual de Victoria Ocampo, cuyo criterio sobre la nueva editorial se impone al que tenían otros informantes de Ortega que, como María de Maeztu o Lorenzo Luzuriaga, veían con buenos ojos el 
emprendimiento e incluso habían participado de él. No hay que olvidar que De Torre siempre admiró a Ortega, ni tampoco que la más perdurable huella de Gonzalo Losada en Espasa Calpe Argentina, la colección Austral, se había iniciado en 1937 con un título del filósofo. Tampoco debe ser obviado que, prácticamente a la vez que Losada, Ocampo estaba lanzando con muchas dificultades, y acompañada de un grupo de industriales conservadores, principalmente españoles franquistas, su propio sello editorial, Sudamericana.

De Torre es una pieza fundamental del nuevo proyecto de Losada. Dirige casi todas las colecciones iniciales: "Biblioteca Contemporánea", "La Pajarita de Papel”, "Cristal del Tiempo", "Panoramas" así como la edición de las Obras Completas de Federico García Lorca. Escribe los textos de acompañamiento de los libros, prólogos y prefacios, encarga y revisa personalmente traducciones... En la práctica, actúa de director editorial. También dirigió la colección "Poetas de España y América" en colaboración con Amado Alonso, con quien tuvo un agrio enfrentamiento a principios de 1941 por los juicios vertidos contra los filólogos en La desconocida del Sena, de Jules Supervielle, publicado en la Biblioteca Contemporánea.

Durante más de treinta años, la editorial Losada será la ocupación principal de Guillermo de Torre, si bien se acompaña de una intensa actividad como crítico en muchas revistas y periódicos de toda América Latina, así como la asunción de cargos tales como el de agregado cultural de la embajada de la República Española en Buenos Aires durante la guerra (Zuleta 1993: 54). El papel desempeñado por Guillermo de Torre se nos revela central en la historia de la editorial hasta el punto de que esta puede dividirse en dos grandes etapas marcadas por el paso de De Torre de la dirección editorial a la mera pertenencia al Directorio de Losada. Esto tiene lugar a partir de su nombramiento, en noviembre de 1955, como profesor universitario, primero en Rosario y luego en la Universidad de Buenos Aires (Zuleta 1962: 18 y 1993: 41). El mismo De Torre lo explica en su correspondencia, en una carta de agosto de 1958: "esas funciones de asesoramiento literario en la Editorial Losada ya no me incumben obligatoriamente, desde el momento en que pasé a formar parte del Directorio y no tenía tiempo para todo", responde a una propuesta de publicación de Ricardo Latcham.

Hasta entonces, Guillermo de Torre había sido el principal artífice de la política y dirección editorial de Losada; había diseñado colecciones y había propuesto directores cuando no las había dirigido él mismo. Su gusto - amplio y refractario a los límites y a las ideas preconcebidas - y su idea editorial está detrás del proyecto, del que Gonzalo Losada es un mero gestor que proporciona la imagen pública de la empresa y que ha delegado en él las decisiones puramente intelectuales. En la introducción a un ensayo sobre la trayectoria intelectual de Guillermo de Torre, una de sus discípulas más destacadas, Emilia Zuleta, distinguía como rasgo principal de sus postulados críticos que “predicó la necesidad de una literatura responsable, contra un seudo compromiso que no respeta la libertad del creador ni el 
principio de la necesidad de la obra. Esa libertad intelectual no excluye la fidelidad que el artista debe a su tiempo" (Zuleta 1993: 7). Esta diferenciación entre responsabilidad y compromiso ("seudo compromiso") se proyectó no solo en su obra crítica sino también en su influencia sobre el rumbo editorial de Losada.

La impronta de Guillermo de Torre es especialmente visible en Losada durante los primeros diez años de la historia de la editorial, hasta aproximadamente 1948, cuando los problemas económicos obligan a restricciones en las publicaciones, comenzando así el final de la llamada "Edad de Oro de la edición argentina” (De Diego 2014). El propio De Torre se lo dice por carta a Enrique Azcoaga en noviembre de 1947: "Probablemente, las cosas en lo sucesivo irán más despacio. Las dificultades son ahora aquí grandes -en el plano económico, se entiende; lo demás, felizmente no nos ha afectado-. Hay ciertas cosas que han mermado gravemente su producción [de la editorial Losada]." Hasta entonces y aún durante algunos años más la editorial atraviesa su época de mayor producción y también la más emblemática. Al no haber restricciones y abundar las ventas, De Torre goza de una amplia autonomía de acción y la injerencia de Gonzalo Losada es mínima. Pueden permitirse ediciones muy costosas, abundantes títulos de las colecciones que tienen menos ventas y, en suma, una elevada producción, como es el caso de "La Pajarita de Papel", una colección casi personal dirigida y cuidada por el propio De Torre.

La posición de De Torre como exiliado — igual que la de Losada o la de López Llausás - es problemática. Él mismo declaró no ser un exiliado, a propósito de lo dicho al respecto en el famoso artículo de José Luis López Aranguren, "La evolución de los intelectuales españoles en la emigración" (De Torre 1953). No obstante, pese a su actitud de tercera vía, representa una fracción importante del exilio que tuvo su reflejo en el catálogo de Losada. En gran medida, la siempre problemática simbolización editorial del exilio en relación con el nacionalismo y con la cultura del país de acogida se resuelve, en el caso de Losada, a través de la visión que del problema tiene Guillermo de Torre. De Torre, que como otros intelectuales liberales había visto su comprometida su posición política durante la guerra, al llegar a Argentina como exiliado, aclara su compromiso con la república y contra el franquismo, como se puede ver en sus colaboraciones con España Republicana, su recopilación de ensayos La aventura y el orden, de 1943, y su dura invectiva contra su admirado Ortega y Gasset cuando este decide regresar. Al mismo tiempo, acerca posiciones con aquellos intelectuales de los que en un cierto momento se sentía aparte por el tema del compromiso, como Rafael Alberti y Pablo Neruda.

El giro en el catálogo de Losada al que alude De Diego en su citado trabajo puede comenzarse a datar por tanto hacia 1955, cuando el predominio de la "literatura responsable" cede en favor de la "literatura comprometida" según los postulados que acabamos de enunciar. Coincide esta fecha, además de con el fin del peronismo, con la renuncia de De Torre a la dirección la editorial y también con otros 
factores. El principal de ellos creemos que es la incorporación de algunos jóvenes españoles que, por su disidencia política, han salido de España franquista: Manuel Lamana, Ricardo Bastid, Víctor Sainz, José Antonio Rial, y, no tan joven y algunos años antes, Enrique Azcoaga. Ninguno de ellos puede considerarse alineado con el lenguaje del realismo social imperante en España. Los libros que en esos años publican en la editorial Losada, de hecho, muestran alternativas muy estimables al lenguaje objetivista que se practicaba, casi exclusivamente, en la narrativa española. Pero salvo alguna excepción sus libros, así como el de otro español, Fernando Morán, sí abordan una temática muy nacional, reproduciendo en Argentina uno de los males de la literatura peninsular: el excesivo localismo, un tanto insularista, aquejado de evidente falta de influencias y de cosmopolitismo como consecuencia del cordón sanitario al que la censura había sometido a su formación como lectores. Es esta una asimilación inconsciente muchas veces, consecuencia de un aprendizaje frustrado que implica un deseo de aprender y de elevar su escritura por encima de aquellas limitaciones. Véase al respecto, por ejemplo, cómo Manuel Lamana, en una carta a Guillermo de Torre, lo felicita por su artículo "Los puntos sobre las íes novelísticas”, en el que De Torre había afeado agriamente el manifiesto-proclama de Juan Goytisolo sobre "Una literatura nacional popular", aparecido en Ínsula.

Con ello, la política editorial de Losada experimenta un cierto giro hacia la literatura española de autores del interior, o bien del segundo exilio. Además de ver publicados los libros de los autores mencionados, se publican los otros escritores españoles del interior como José Hierro o Dionisio Ridruejo. Y Lamana hace una gestión por publicar algunas obras de Marcel Saporta, exiliado de los años cuarenta, autor, bajo seudónimo de Elfin de la esperanza, que llegaría a ser un escritor relevante. Pese a su afán de novedad, estos jóvenes, que van copando puestos destacados dentro de la editorial, carecen de la cultura literaria de De Torre y sus contactos americanos son mucho más limitados. Se han educado en los axiomas del realismo social y, aunque en las novelas que escriben en su exilio y publican en Losada se alejan parcialmente de consignas objetivistas que, en aquellos finales de los cincuenta, están en pleno auge en España, no son igualmente ajenos a una escritura mucho más coyuntural y explícita. Por otra parte, su conocimiento de la literatura no española es muy escaso.

Losada, por su parte, no se olvida de que la legitimidad de su catálogo se la dan los nombres con los que nutrió su catálogo en los años cuarenta -Camus, Asturias, Alberti, Neruda, Juan Ramón...- y no ve el potencial renovador que tienen algunos autores jóvenes que, como Julio Cortázar, que ya está publicando sus libros por entonces en Sudamericana. Mientras De Torre se enfrenta de una manera pública con el dogma real-socialista que impera en la literatura española peninsular entre 1958 y 1963 (años de sus polémicas con Juan Goytisolo y, después, con José Ramón Marra-López) en Losada se va gestando un cambio tanto en la perspectiva españolista de la editorial como en sus posiciones estéticas. 
En esos años, De Torre viaja varias veces a España, donde pasa largas temporadas. En una de esas estancias, a finales de 1958, es informado por carta a través del poeta Luis Alejandro, otro español, de origen canario, que trabaja en Losada. En la carta, con fecha del 20 de noviembre de 1958, Alejandro informa del resultado del Primer Concurso de Premios de Novela Losada, del que resultó ganador un español, Cecilio Benítez de Castro -antiguo falangista asentado en Buenos Aires y ahora convertido al peronismo más radical- por La iluminada, siendo finalistas varios autores argentinos (como David Viñas), españoles del interior (Francisco Valle de Juan) y del exilio (Esteban Salazar Chapela, Ricardo Bastid) y otros autores latinoamericanos (Manuel Mejía Velasco). La noticia tiene importancia porque las novelas premiadas y finalistas constituyeron casi todas las novedades publicadas en narrativa por Losada en ese año y el año siguiente. Posiblemente, ante la asistencia continuada de De Torre, Gonzalo Losada había decidido fiarse del criterio del jurado (Bioy Casares, Beatriz Guido...). Pero la realidad es que la mayoría de las novelas no merecían la publicación y, probablemente no la habrían alcanzado si Guillermo de Torre hubiera estado presente en el proceso.

¡Qué diferente con el premio Ricardo Güiraldes, que la editorial había constituido al poco de iniciar su andadura y que, en su primera edición había premiado Es dificil empezar a vivir, de Bernardo Verbitsky, novela de un corte realista muy en boga en aquellos años, siendo finalista Tierra de nadie, de Juan Carlos Onetti! La reseña de la novela de Bernardo Verbitsky, en el número 2 de Blanco y Negro (junio-julio 1941), boletín de la editorial, comenzaba con esta afirmación

La Editorial Losada, S. A., movida por el deseo de estimular la revelación de nuevos escritores argentinos, convocó, bajo el Premio Ricardo Güiraldes, un concurso de novelas. El jurado compuesto por Norah Lange, en nombre de la Sociedad Argentina de Autores; Jorge Luis Borges, en representación de los autores y Guillermo de Torre por la editorial Losada, acordó otorgar dos premios.

Aparte de la heterogeneidad de las dos novelas premiadas, llama la atención la necesidad de encontrar una vanguardia en Argentina. Empeño que no se consiguió con el Premio Internacional casi dos décadas después.

Por aquellos años, De Torre está mucho más empeñado en sacar adelante otro proyecto editorial, el de la colección El Puente, que no llevará el sello de Losada sino el de Edhasa, filial española de Sudamericana, y que difiere de su firme compromiso con el exilio en los primeros años. En un intercambio de cartas a finales de 1962 y principios de 1963, Gonzalo Losada y De Torre tienen una discrepancia seria: "mi opinión es que las personas que ejercen funciones directivas en una editorial no pueden ejercer cargos semejantes en otras porque, se quiera o no se quiera, a la larga pueden producirse suspicacias en punto a compatibilidades que, si se procede de buena fe, nunca pueden llegar a adquirir gravedad pero que sí pueden resultar molestas", le escribe Losada intentando zanjar la cuestión. El 
desencuentro, en cualquier caso, marca un punto de inflexión en la implicación de De Torre en la editorial, muy mermada ya por entonces.

Es el momento de crisis de la editorial, que hasta entonces había sido la vanguardia de la cultura escrita en América Latina. En esta coyuntura, Losada toma varias decisiones fundamentales: fiar, en narrativa, todo a los premios que instituye, arriesgar poco o nada con nuevos nombres y afianzar las marcas ideológicas de su catálogo, reforzando el sesgo social y político. Los títulos importantes de la editorial a partir de los sesenta serán obras efectivamente comprometidas, que pueden tener una retórica compleja y vanguardista, pero que quedarán al margen de la corriente principal del boom a causa de su adhesión política. Serán obras de antiguos autores de la casa, como José María Arguedas, que publica Los ríos profundos (1958) y El zorro de arriba y el zorro de abajo (1971), y Miguel Ángel Asturias, o de las raras veces que el premio halle un autor perdurable, como fue el caso, en 1959 (publicada en 1960), de Hïo del hombre, de Augusto Roa Bastos. Curiosamente, estas obras (y quizá alguna más) representan la vía menos comercial y celebrada de la literatura latinoamericana de su momento, la que se inserta de una manera más clara la cultura prehispánica para hallar formas vanguardistas en el empleo del lenguaje y hallan en ello motivo para una reivindicación política. Y se reeditan bastantes obras publicadas en un realismo indigenista muy en boga en los años iniciales de la editorial cuya primera edición no había sido de Losada, como Huasipungo, de Jorge de Icaza (1934; edición de Losada: 1960) y El mundo es ancho y ajeno, de Ciro Alegría (1941; edición en Losada, 1961), Tampoco aciertan con las apuestas más claras en la senda de la renovación, como la de Enrique Anderson Imbert. Frente a una visión más internacionalista y europeizante, que representan los autores emblemáticos del boom, Losada va arrinconándose cada vez al margen de la novedad y subsistiendo, hasta hoy, de su fondo editorial.

Da la sensación, efectivamente, de que a partir de 1960 hay un viraje hacia la literatura comprometida muy evidente. Entre las evidencias de ello, en Negro sobre Blanco hayamos un reportaje de Ricardo Bastid sobre este tema en teatro, a propósito de la revista Primer Acto de Madrid, en la que hay una alabanza a la moda del neorrealismo italiano cuando este ya estaba de capa caída incluso en España. Otro momento en el que se evidencia el giro puede ser el discurso de entrega del II Premio de novela Losada a Augusto Roa Bastos por Hïo del hombre, en 1960, reproducido en Negro sobre Blanco, y en el que Bastid hace una defensa muy cerrada del compromiso político en literatura a propósito de la obra premiada. A partir de entonces, los premios de la editorial recaen en obras muy menores, de las que se resalta sobre todo el carácter comprometido, sin aludir apenas a su valor literario. En 1961 son vencedora y finalista respectivamente Detrás del grito, de Iverna Codina, y Unos cuantos días, de Luis Pico Estrada. De la primera, una novela social de mineros en Mendoza, el boletín de la editorial declara que "la autora concibe la literatura como testimonio y compromiso"; de la segunda, que es un "análisis 
moroso del aburrimiento de un adolescente de la alta burguesía, lúcido pero abúlico, incapaz de comunicarse y poblar el vacío en que transcurre su vida".

También se observa en la editorial un aumento de la presencia de temas españoles, en detrimento del balance medido que siempre se había observado entre el pensamiento y la cultura latinoamericana y la española. Esto es especialmente observable en el campo del ensayo político. La colección "Cristal del Tiempo" publica casi simultáneamente, en 1962, Escrito en España, de Dionisio Ridruejo, El pensamiento español contemporáneo, de Luis Araquistain, y Cartas a un escultor, de Indalecio Prieto. Los presenta así: "La Editorial Losada, coincidente con la dramática situación por que atraviesa España, presenta en su colección 'Cristal del Tiempo' tres obras fundamentales redactadas por políticos de reconocida actuación liberal”.

Al mismo tiempo, se observa un pesimismo creciente en Gonzalo Losada, muchos puntos por encima de las habituales quejas de los editores por las sempiternas dificultades de su negocio, que explican el miedo a la innovación y a arriesgar con nuevos nombres. Encontramos estas lamentaciones, por ejemplo, en el discurso de entrega de los premios de novela del año 1962: "Se me ocurre que si las cosas siguen por este camino, escritores, traductores, artistas y artesanos tendremos que optar, como en pasados tiempos, por la vida monacal o por la militar para poder ayudarnos en algo que merezca, por lo menos, respeto a nuestros conciudadanos...". Losada por entonces es ya casi septuagenario. Doce años después, en 1974, todavía al frente de la editorial, publica un texto en La Opinión Cultural bajo el título de "Con el corazón a los cuatro vientos". Es un testimonio y una rememoración en la que se pone de manifiesto hasta qué punto ha quedado anclado en un ambiente literario y en unas prácticas editoriales ya preteridos, propios de los años cuarenta. Él mismo reconoce que se hizo editor por casualidad y en un tiempo sin representantes ni agentes, en el que los libros se contrataban "en una reunión casi familiar que celebró Capdevila”, "en lo de Girondo”, “en la Isla Negra, en casa de Neruda”... (Losada, 1974: 10). Para entonces, Guillermo de Torre lleva ya tres años muerto y los tiempos de la edad de oro editorial quedan ya lejos. Pero uno advierte que aquel sello que lleva su nombre se había forjado a partes iguales por su excelente gestión pero también por la alta calidad intelectual de sus asesores. Y que ahora, editor del mundo de tertulias, pero no de la gran industria globalizada, Losada habla con nostalgia sin comprender aquella nueva época de best-sellers y enormes tiradas.

Ese pesimismo lleva a Losada a un conservadurismo radical en su plan de publicaciones que determinará fatalmente la crisis casi definitiva de la editorial. La expresión más cruda está en una carta que le envía a De Torre en octubre de 1965, en una de las estancias de este en Madrid:

Cada vez estoy más convencido de que hay que endurecerse, ajustando más las publicaciones a la realidad de su posible venta, reduciendo al mínimo la obra de mecenazgo que en gran parte hemos venido realizando con muy limitado reconocimiento por parte de los beneficiarios y del 
Fernando Larraz. Guillermo de Torre y el catálogo...

público en general. En la medida en que podamos y seamos capaces de ajustar nuestra conducta a este principio severamente comercial que también estoy convencido lo será al mismo tiempo cultural, podremos o no sobrevivir. Ya no es posible seguir haciendo libritos de literatura, de poesía, ensayos, etc. que no interesan a nadie pero que cuestan mucho dinero y ocupan mucho espacio.

Parecería difícil atribuir este fragmento a un editor que sacó adelante tantos y tan valiosos títulos, muchos de ellos sumamente arriesgados. También parece insólito que el artífice de una de las editoriales más prestigiosas en lengua española y que había obtenido tantos beneficios como Losada se queje de la ingratitud de los lectores y de la falta de lectores. Evidentemente los años sesenta no son ni social ni económicamente los mejores para Argentina, pero son años de profundas transformaciones y oportunidades editoriales en la cultura escrita en lengua española, cambios para los que Losada demuestra no estar preparado. No sabemos qué habría pasado si De Torre hubiera seguido como asesor de la editorial. Probablemente, el retraimiento de Losada se habría impuesto. Pero la aguda crisis de títulos de Losada acaso no habría sido tan aguda.

El proceso determina el futuro de la editorial y conllevará que ningún director editorial tenga la autonomía de la que gozó De Torre. No es de extrañar pues que en una entrevista de abril de 1976, Jorge Lafforgue, que es por entonces asesor editorial, declare que no tiene margen de maniobra: "las pautas de la empresa y los requerimientos del mercado marcan necesaria y fuertemente mi labor". Se trata de juicios duros contra la editorial para la que Lafforgue trabaja, a la que critica por vivir de la inercia y de no arriesgarse, de obligarle a rechazar a "muchos autores jóvenes, varios de ellos amigos míos, que comienzan a conformar el actual panorama de la literatura continental y cuyos originales me vi obligado a declinar”. Y termina preguntándose: “¿Puedo oponerme por ejemplo a las seguras reediciones de Horacio Quiroga, García Lorca o Albert Camus en favor de las riesgosas novedades? ¿Puedo -es un ejemplo hipotético- rechazar una novela de Jorge Amado so pretexto de que no me satisface su escritura cuando sé que su venta es enorme?” (Lafforgue 1976: 10).

Parece inconcebible que Guillermo de Torre se hubiera planteado estos interrogantes allá por la década de 1940, cuando la editorial publicaba los libros de algunos jóvenes y prometedores escritores. Las circunstancias son otras, desde luego, pero también es el envejecimiento y creciente conservadurismo de un sello en un contexto en que lo nuevo, representado por los jóvenes García Márquez, Vargas Llosa, Fuentes, Donoso, Puig... estaba siendo editado en otros sellos de la competencia. 
Fernando Larraz. Guillermo de Torre yel catálogo...

\section{Bibliografía}

Alemany Bay, Carmen (1998). La polémica del meridiano intelectual de Hispanoamérica (1927): estudio y textos. Alicante: Publicaciones de la Universidad.

Campomar Fornieles, Marta. "El exilio argentino en la correspondencia de Ortega y Gasset: la crisis de las etimologías”. Revista de Estudios Orteguianos 20, (2010): 101-157.

De Diego, José Luis (2014). “La 'época de oro de la industria editorial’. De Diego, José Luis (ed.). Editores y políticas editoriales en Argentina (1880-2010). Buenos Aires: Fondo de Cultura Económica: 97-133.

De Diego, José Luis (2015). La otra cara de Jano. Buenos Aires: Ampersand.

De Lara, Juan Jacobo (ed.) (1983). Pedro Henríquez Ureña y Alfonso Reyes. Epistolario íntimo (Tomo III). Santo Domingo: Universidad Nacional Pedro Henríquez Ureña.

De Torre, Guillermo. "Hacia una reconquista de la libertad intelectual”. La Torre 3 (1953): 107-126.

Durán, Manuel. “En vanguardia de la cultura: apuntes para una historia de Austral”. Ínsula 622 (1998): $2-3$.

García, Carlos y Sanz Álvarez, M. Paz (eds.) (2012). Gacetas y Meridianos. Correspondencia Ernesto Giménez Caballero/Guillermo de Torre (1925-1968). Madrid: Iberoamericana.

Lafforgue, Jorge. La Opinión Cultural, 4 de abril de 1976: 10.

Larraz, Fernando. "Política y cultura. Biblioteca Contemporánea y Colección Austral, dos modelos de difusión cultural”. Orbis Tertius XIV, 15 (2009).

López Vega, Antonio (ed.) (2008). Epistolario inédito, Marañón, Ortega, Unamuno. Madrid: Espasa Calpe.

Losada, Gonzalo. "Con el corazón a los cuatro vientos”. La Opinión Cultural. 8 de septiembre de 1974: 10.

Martínez Rus, Ana. "La industria editorial española ante los mercados americanos del libro 1892-1936”. Hispania: Revista Española de Historia 62, 212 (2002): 1021-1058.

Ocampo, Victoria. "Vida de la revista Sur. 35 años de una labor”. Sur 303-304-305 (1966): 1-9.

Zuleta, Emilia de (1962). Guillermo de Torre. Buenos Aires: Ediciones Culturales Argentinas.

Zuleta, Emilia de (1993). Guillermo de Torre entre España y América. Mendoza: Editorial de la Universidad Nacional de Cuyo. 